\title{
Metabolic engineering strategy for synthetizing trans-4-hydroxy-L-proline in microorganisms
}

\author{
Zhenyu Zhang ${ }^{1 \dagger}$, Pengfu Liu ${ }^{1 \dagger}$, Weike Su ${ }^{1,2}$, Huawei Zhang ${ }^{2}$, Wenqian $\mathrm{Xu}^{1}$ and Xiaohe $\mathrm{Chu}^{1{ }^{*}}$ (D)
}

\begin{abstract}
Trans-4-hydroxy-L-proline is an important amino acid that is widely used in medicinal and industrial applications, particularly as a valuable chiral building block for the organic synthesis of pharmaceuticals. Traditionally, trans-4-hydroxyL-proline is produced by the acidic hydrolysis of collagen, but this process has serious drawbacks, such as low productivity, a complex process and heavy environmental pollution. Presently, trans-4-hydroxy-L-proline is mainly produced via fermentative production by microorganisms. Some recently published advances in metabolic engineering have been used to effectively construct microbial cell factories that have improved the trans-4-hydroxy-L-proline biosynthetic pathway. To probe the potential of microorganisms for trans-4-hydroxy---proline production, new strategies and tools must be proposed. In this review, we provide a comprehensive understanding of trans-4-hydroxy-L-proline, including its biosynthetic pathway, proline hydroxylases and production by metabolic engineering, with a focus on improving its production.
\end{abstract}

Keywords: Trans-4-hydroxy-L-proline, Biosynthetic pathway, Proline hydroxylases, Metabolic engineering

\section{Background}

Hydroxyprolines are a series of hydroxylated derivatives of proline comprising six isomers-trans-4-hydroxyL-proline ( $t 4 \mathrm{Hyp})$, trans-3-hydroxy-L-proline ( $t 3 \mathrm{Hyp})$, cis-4-hydroxy-L-proline (c4Hyp), cis-3-hydroxy-L-proline (c3Hyp), trans-5-hydroxy-L-proline (t5Hyp), and cis-5-hydroxy-L-proline (c5Hyp) (Fig. 1). Furthermore, $t 4 \mathrm{Hyp}$ is a major amino acid in collagen proteins, which contain two $\alpha 1$ and one $\alpha 2$ polypeptide chain, to allow the sharp twisting of the collagen helix and are the major extracellular components of connective tissues, such as skin, tendon, cartilage, blood vessels, and bone. The helical region of collagen comprises Gly-X-Y repeats, with

\footnotetext{
*Correspondence: chuxhe@zjut.edu.cn

†Zhenyu Zhang and Pengfu Liu contributed equally to this work

${ }^{1}$ Collaborative Innovation Center of Yangtze River Delta Region Green

Pharmaceuticals, Zhejiang University of Technology, Hangzhou 310014, Zhejiang, People's Republic of China

Full list of author information is available at the end of the article
}

$t 4$ Hyp being present only in the Y position [1]. T4Hyp was previously considered to have little nutritional significance but is now thought to be a major precursor for the synthesis of glycine, pyruvate, and glucose. Some evidence supports the ability of $t 4 \mathrm{Hyp}$ to scavenge oxidants, regulate the state of cellular reduction and stimulate the expression of anti-oxidative enzymes in the cell [2,3]. T4Hyp is required for normal secretion after protein synthesis and contributes to the integrity of the triplehelical conformation [4]. In animals, $t 4$ Hyp is produced by the posttranslational hydroxylation of proline residues in proteins $[5,6]$. T4Hyp is a nonessential $\alpha$-amino acid and is present in several secondary metabolites (e.g., echinocandins and etamycin) [7]. Additionally, $t 4 \mathrm{Hyp}$ has been widely used in the medicine, biochemistry, food, and cosmetic industries and is usually used as a valuable building block for the synthesis of many pharmaceuticals [8]. T4Hyp can be used to synthesize many compounds, such as glutamic acid analogs, kainoid analogs 
(a class of nonproteinogenic amino acids with a broad spectrum of biological activities), arginine analogs, and pipecolic acid and its derivatives (which play important biological roles as components of peptides, proteins, and intermediates for the synthesis of conformationally constrained molecular scaffolds) through diastereoselective synthesis, $N, N^{\prime}$-dioxides, carbapenem antibiotics (imipenem, meropenem, panipenem), angiotensin-converting enzyme inhibitors, $N$-aryl pyrroles (important organic compounds for medicinal and material sciences), oxaceprol (an atypical inhibitor of inflammation used for the treatment of conditions affecting the connective tissues, such as osteoarthritis), oligomers, and macrocycles (usually used as valuable sources of bioactive molecules that have properties such as good solubility and metabolite stability for drug discovery) (Fig. 2) [9-18].

\section{Artificial biosynthetic pathway of trans-4-hydroxy-L-proline in Escherichia coli and Corynebacterium glutamicum}

The main types of microorganisms currently used to produce t4Hyp are Escherichia coli and Corynebacterium glutamicum (Fig. 3) [19]. In particular, because of a lack of proline hydroxylases, proline hydroxylase is introduced into E. coli and C. glutamicum and exogenously expressed to form a complete $t 4 \mathrm{Hyp}$ synthesis pathway. Glucose as a substrate undergoes a series of biochemical reactions to produce $\alpha$-ketoglutarate $(\alpha-K G)$. Subsequently, $\alpha-K G$ is catalyzed to form glutamate via glutamate synthase. The synthesis pathway from glutamate to proline requires three enzymatic reactions (Fig. 4) [20]. First, glutamate is catalyzed to $\gamma$-glutamyl phosphate by $\gamma$-glutamyl kinase. This enzyme is the rate-limiting enzyme of proline synthesis and can be inhibited by proline feedback [21]. Typically, the enzyme is a homotetramer of a 367-amino acid polypeptide comprising an N-terminal 257-residue amino acid kinase (AAK) domain along with a 110-residue PUA (named for pseudo uridine synthases a

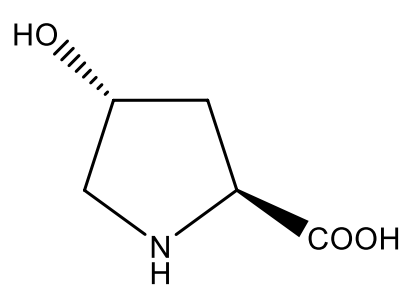

trans-4-hydroxy-L-proline b

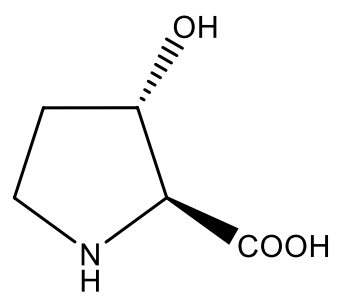

trans-3-hydroxy-L-proline c

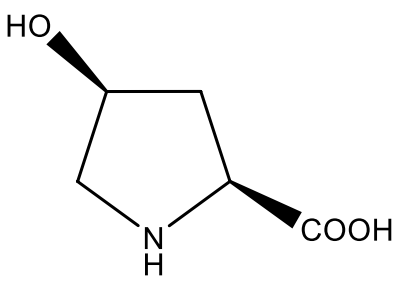

cis-4-hydroxy-L-proline d

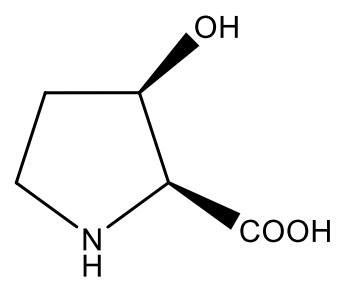

e<smiles>O=C(O)[C@@H]1CC[C@@H](O)N1</smiles>
cis-3-hydroxy-L-proline, and e 5-hydroxy-L-proline 
a

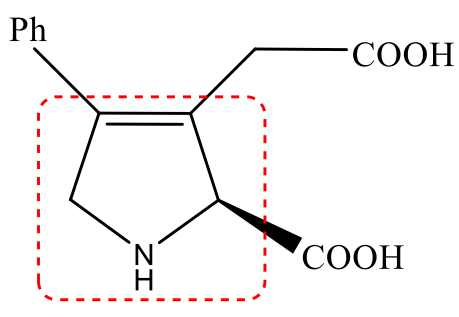

kainoid analogues

c

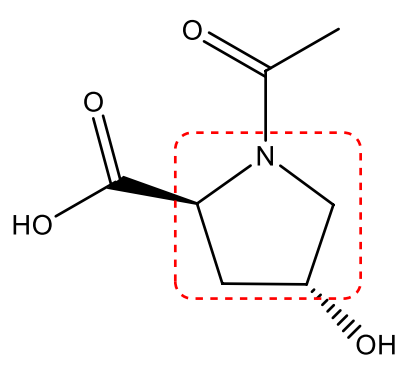

$\mathrm{N}$-acetyl hydroxyproline

e

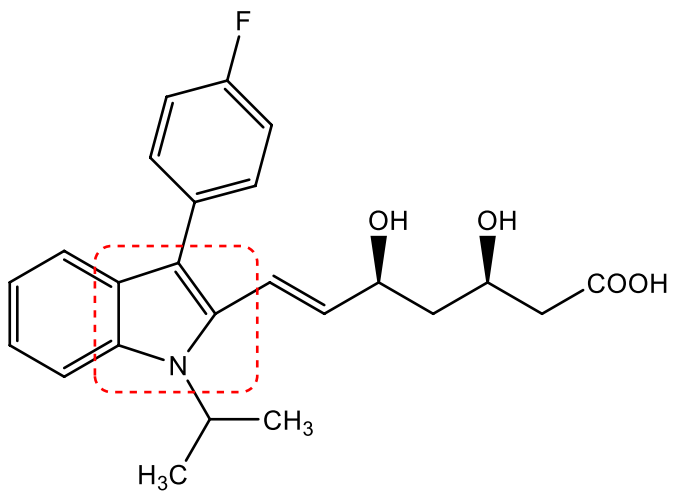

fluvastatin

d b

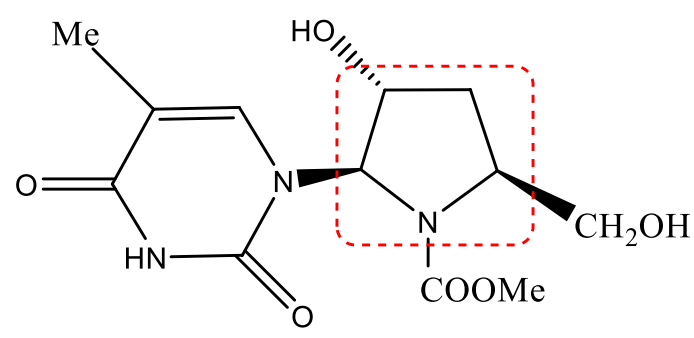

pyrrolidine derivatives

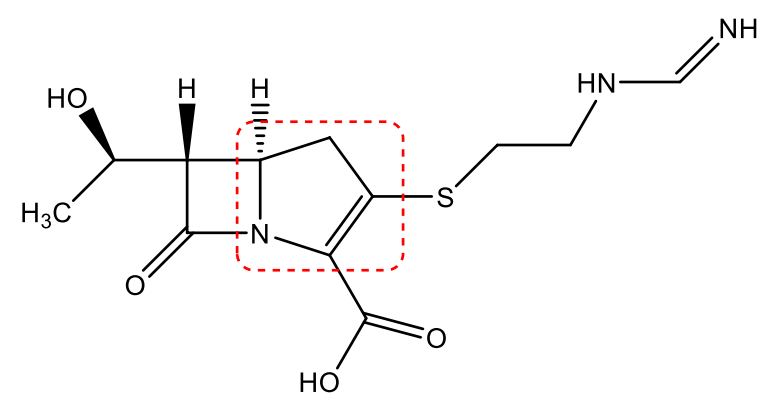

imipenem

f

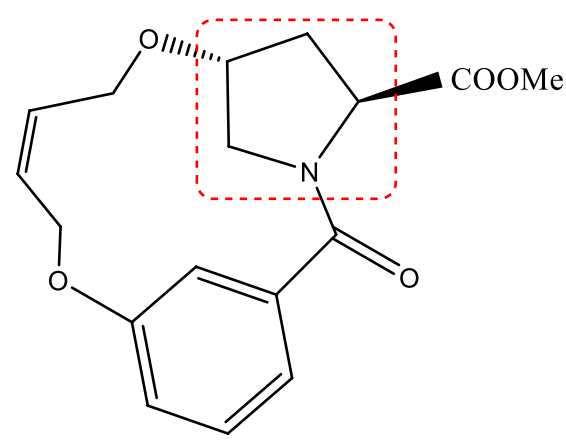

macrocycle

Fig. 2 Compounds for which the parent structure is hydroxyproline

and archaeosine-specific transglycosylases) domain [22]. Glutamate- $\gamma$-semialdehyde dehydrogenase catalyzes the second reaction of proline biosynthesis and activates $\gamma$-glutamyl phosphate to glutamate- $\gamma$ semialdehyde. The enzyme is not susceptible to either end-product prohibition or inhibition by proline [23]. $\gamma$-Glutamyl kinase and glutamate- $\gamma$-semialdehyde dehydrogenase occur in a complex, and $\gamma$-glutamyl kinase activity is undetectable in the absence of glutamate- $\gamma$-semialdehyde dehydrogenase $[24,25]$. Glutamate- $\gamma$-semialdehyde then cyclizes spontaneously to form pyrroline-5-carboxylate (an internal Schiff base). In the third reaction of the proline biosynthetic 


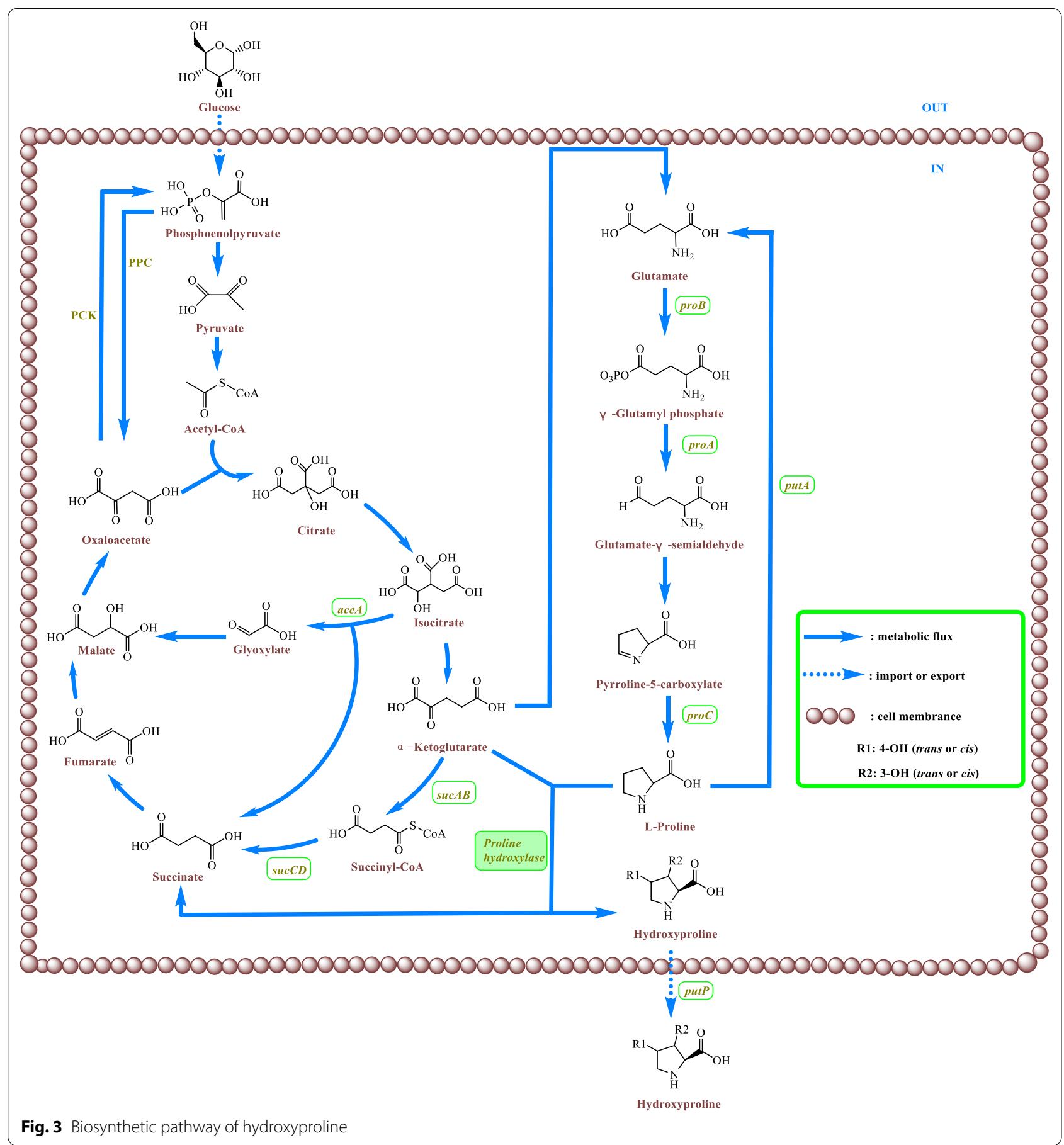

pathway, pyrroline-5-carboxylate is reduced to proline by pyrroline-5-carboxylate reductase. Pyrroline-5-carboxylate reductase mediates the pyridine nucleotidelinked reduction of pyrroline-5-carboxylate to proline but not the reverse reaction, even at high substrate concentrations. NADPH and NADH are both cofactors of pyrroline-5-carboxylate reductase, and NADPH demonstrates higher activity than NADH [26].

\section{Catabolism of proline}

Proline can be catabolized to glutamate through two enzymatic steps (Fig. 5). The E. coli PutA protein comprises 1320 amino acid residues, and its dimer has a 


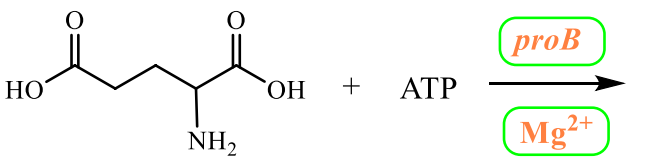

Glutamate<smiles>NC(CCC(=O)O[Na])C(=O)O</smiles>

Y -Glutamyl phosphate<smiles></smiles>

Y -Glutamyl phosphate<smiles>c1ccccc1</smiles><smiles>NC(CCC=O)C(=O)O</smiles>

Glutamate- $Y$-semialdehyde
$+\mathrm{NADP}^{+}+\mathrm{Pi}$

spontaneous

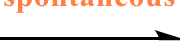<smiles>O=C(O)C1CCC=N1</smiles>

Pyrroline-5-carboxylate

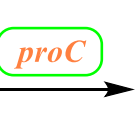

L-Proline

Fig. 4 Synthesis pathway from glutamate to proline
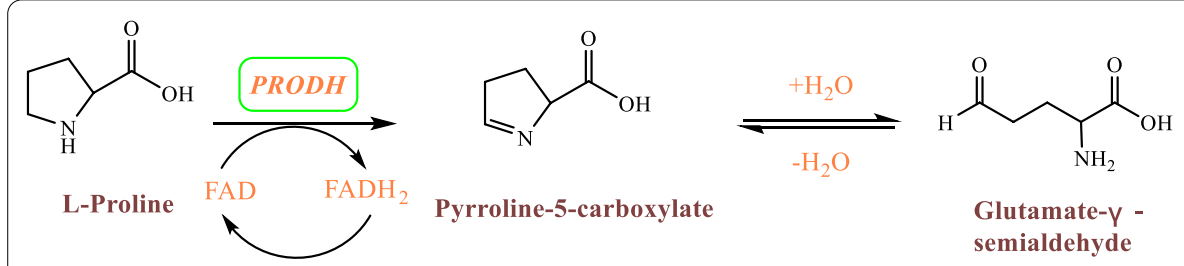

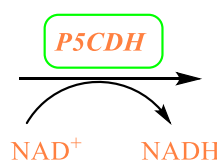

NAD

$\mathrm{H}_{2} \mathrm{O}$<smiles>NC(CCC(=O)O)C(=O)O</smiles>

Glutamate

Fig. 5 Proline is catabolized to glutamate via two enzymatic steps. $P R O D H$ proline dehydrogenase, $P 5 C D H$ pyrroline-5-carboxylate dehydrogenase

molecular mass of $293 \mathrm{kDa}$ [27]. PutA is a multifunctional flavor-protein that is both a membrane-associated proline catabolic enzyme and a transcriptional repressor of a pair of genes encoding proline utilization proteins [28]. The first enzymatic step is that proline is catalyzed to generate pyrroline-5-carboxylate by PutA. The electrons from reduced FAD are subsequently transferred to an acceptor in the electron transport chain to complete the catalytic cycle. In the second step of reaction, non-enzymatic hydrolysis of pyrroline-5-carboxylate generates glutamic semi-aldehyde; subsequently, glutamic semi-aldehyde is oxidized to glutamate through the transfer of two electrons to reduce $\mathrm{NAD}^{+}$to NADH [29]. There is some evidence that PutA has DNA-binding 
activity and serves as a transcriptional repressor of the putP and putA genes (proline utilization regulon) in $E$. coli [27]. In E. coli, the regulation of put genes relies on the concentration of proline and intracellular location of the PutA protein [30]. In the presence of proline, the localization of PutA changes from the cytoplasm to the membrane. The transcription of put genes is then activated, and proline is oxidized to glutamate [31]. In the absence of proline, PutA accumulates in the cytoplasm and inhibits the transcription of the put genes through binding to promoter sequences in the intergenic DNA region [32].

\section{Proline hydroxylases}

In mammalian systems, prolyl hydroxylases hydroxylate L-proline residues to Hyp residues, which are involved in collagen biosynthesis, through posttranslational modification of procollagen [33]. The prolyl hydroxylases can be as oxygen sensors, due to the sensitivity to graded levels of oxygen with a strikingly low $\mathrm{O}_{2}$ affinity $(\mathrm{a} \mathrm{Km}$ of $178 \mathrm{~mm} \mathrm{Hg}$ ), which is above the concentration of dissolved $\mathrm{O}_{2}$ in the air) and obvious effects of small changes in oxygen concentration on enzymatic activity were observed [34-36]. However, these prolyl hydroxylases accept peptidyl proline, not free L-proline, as a substrate. By contrast, in microbial system, proline hydroxylases exclusively convert free proline to Hyp [37]. Additionally, proline hydroxylases require $\alpha-\mathrm{KG}$ and $\mathrm{O}_{2}$ as cosubstrates and $\mathrm{Fe}^{2+}$ as a cofactor, and they are also called Fe(II)/ $\alpha$-ketoglutarate-dependent hydroxylases(Fig. 6) [38]. Proline hydroxylases from microorganisms usually participate in the modification of proline and biosynthesis of antibiotics [39]. To date, four different types of L-proline hydroxylases have been identified in microorganisms, L-proline trans-3-hydroxylase (trans- $\mathrm{P} 3 \mathrm{H}$, from an uncultured bacterium esnapd13 and Glarea lozoyensis) [40, 41], L-proline trans-4-hydroxylase (trans-P4H, from
Dactylosporangium sp.RH1) [42], L-proline cis-3-hydroxylase (cis- $\mathrm{P} 3 \mathrm{H}$, from the Streptomyces sp. strain TH1) [43], and L-proline cis-4-hydroxylase (cis-P4H, from Mesorhizobium loti and Sinorhizobium meliloti) [44], and convert L-proline to generate trans-3-hydroxy-L-proline, trans-4-hydroxy-L-proline, cis-3-hydroxy-L-proline, and cis-3-hydroxy-L-proline, respectively. Among these hydroxylases, trans- $\mathrm{P} 4 \mathrm{H}$ has been used in large-scale industrial applications of trans-4-hydroxy-L-proline [38]. Thus far, the structure of trans-P4Hs remains to be elucidated, while the overall structure of cis- $\mathrm{P} 4 \mathrm{H}$ from Mesorhizobium loti and cis-P3H from Streptomyces sp. TH1 were solved (Fig. 7). The active site comprised a twisted jelly roll $\beta$-sheet core, sandwiched by the $\mathrm{N}$-terminal and C-terminal $\alpha$-helical domains (Fig. 8) [45]. The characteristics of these hydroxylases should be noted, including the kinetic parameters, influence of catalase, ascorbate, $\alpha-K G$ substrate, ferrous iron, EDTA, metal salts, organic acids, $\mathrm{pH}$, and temperature. Based on the observation of the decrease of the substrates, The apparent $\mathrm{Km}$ of trans$\mathrm{P} 4 \mathrm{H}$ from Dactylosporangium sp.RH1 is calculated as $0.2 \mathrm{~s}^{-1} \mathrm{mM}^{-1}$ [46]. Interesting, different research results were obtained about the effects of catalase and ascorbate on hydroxylation, the relative mechanism needed further study. For 2-oxoacid-dependent dioxygenase-mediated reactions, the stimulation of $\mathrm{P} 4 \mathrm{H}$ was realized by catalase via scavenging of detrimental peroxide and for many of the 2-oxoacid-dependent dioxygenase family, ascorbate is necessary to obtain a high rate of catalysis $[47,48]$. Onishi et al. found that catalase does not stimulate the turnover of L-proline; however, ascorbate can activate $\mathrm{P} 4 \mathrm{H}$, which is isolated from S. griseoviridus P8648 [37]. By contrast, Lawrence et al. found that $0.2-1 \mathrm{mg} / \mathrm{mL}$ of catalase causes a $20-30 \%$ increase in the turnover of L-proline, whereas $1 \mathrm{mM}$ ascorbate has a toxic effect because ascorbate competes for the same binding site between $\alpha-K G$ and hydroxylase [49]. However, superfluous ascorbate

R1: 4-OH (trans or cis)

R2: 3-OH (trans or cis)

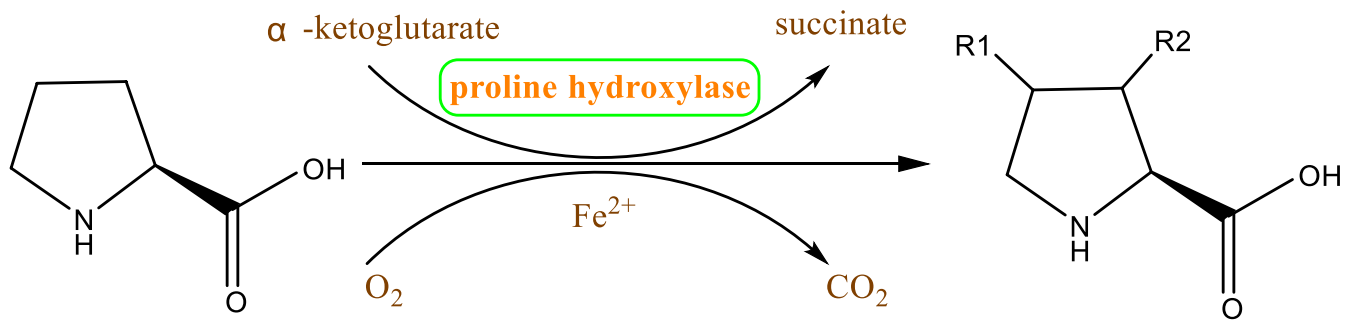

Fig. 6 Hydroxylation of proline hydroxylase requires proline, with a-ketoglutarate, $\mathrm{Fe}^{2+}$, and $\mathrm{O}_{2}$ as cosubstrates 


\section{$\mathbf{a}$}

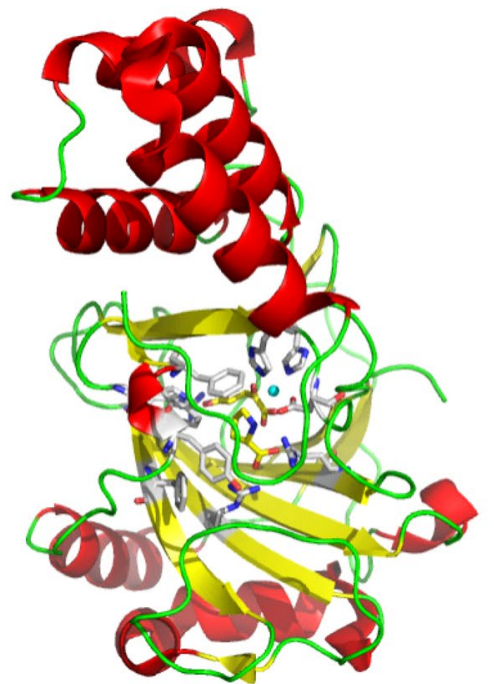

b
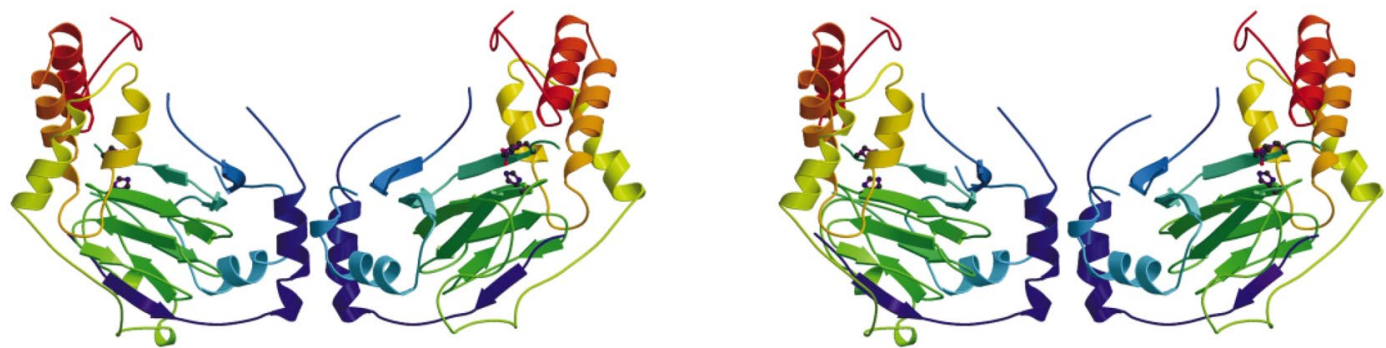

Fig. 7 Protein structure. a L-proline cis-4-hydroxylase. $\mathbf{b}$ L-Proline cis-3-hydroxylase shown in stereo, with the dimer formed by the A and B molecules

cannot inhibit the activity of hydroxylase in the Dactylosporangium sp. strain RH1 [42]. Mori et al. suggested that ascorbate is not necessary for the hydroxylation reaction but can accelerate hydroxylation. $\alpha-K G$ and ferrous ions are strictly required for hydroxylases [43]. If $\alpha-K G$ is replaced with $0.5 \mathrm{mM}$ 2-oxopentanoate, 2-oxoadipate, pyruvate or 2-oxomalonate, L-proline hydroxylation does not occur [49]. These results indicate that hydroxylases belong to the $\alpha$-ketoglutarate-dependent dioxygenase family. The addition of EDTA (a chelator of divalent cations) and divalent cations $\left(\mathrm{Zn}^{2+}, \mathrm{Cu}^{2+}, \mathrm{Ni}^{2+}, \mathrm{Co}^{2+}, \mathrm{Mg}^{2+}\right.$, and $\mathrm{Mn}^{2+}$ ) strongly inhibits enzyme activity [41, 43, 44], indicating that these metal ions act as competitive inhibitors with $\mathrm{Fe}^{2+}$ and that this sensitivity is a common characteristic of members of the $\alpha$-ketoglutarate-dependent dioxygenase family. The addition of citric acid inhibits the hydroxylation reaction; however, succinate does not inhibit this reaction [43]. The effects of $\mathrm{pH}$ and temperature on hydroxylases were also investigated. Maximal activities were achieved at a $\mathrm{pH}$ and temperature of approximately 7.0 and $25{ }^{\circ} \mathrm{C}$, respectively [41, 44]. An improvement in hydroxylase-specific activity was observed when proline is supplied to the medium compared with when the medium is not supplemented, indicating an induction effect of proline [41].

\section{Metabolic engineering approaches for trans-4-hydroxy-L-proline production (Table 1)}

T4Hyp can be produced in different ways (e.g., chemical synthesis or extraction), but these methods are associated with high cost, environmental pollution, and low productivity $[50,51]$. Thus, $t 4$ Hyp production by metabolic engineering may be a competitive approach. Thus far, $t 4 \mathrm{Hyp}$ production by microorganisms has been widely studied.

\section{Optimization, genome mining and evolution of hydroxylases}

The crucial factors for converting L-proline to $t 4 \mathrm{Hyp}$ are hydroxylases, which are promising targets to improve the hydroxylation efficiency to obtain a higher $t 4$ Hyp titer and productivity. Because the hydroxylase gene from the Dactylosporangium sp. strain RH1 has a high GC content and induces rare codons in E. coli, it is poorly expressed in E. coli. The $5^{\prime}$ end of the proline 4-hydroxylase gene 


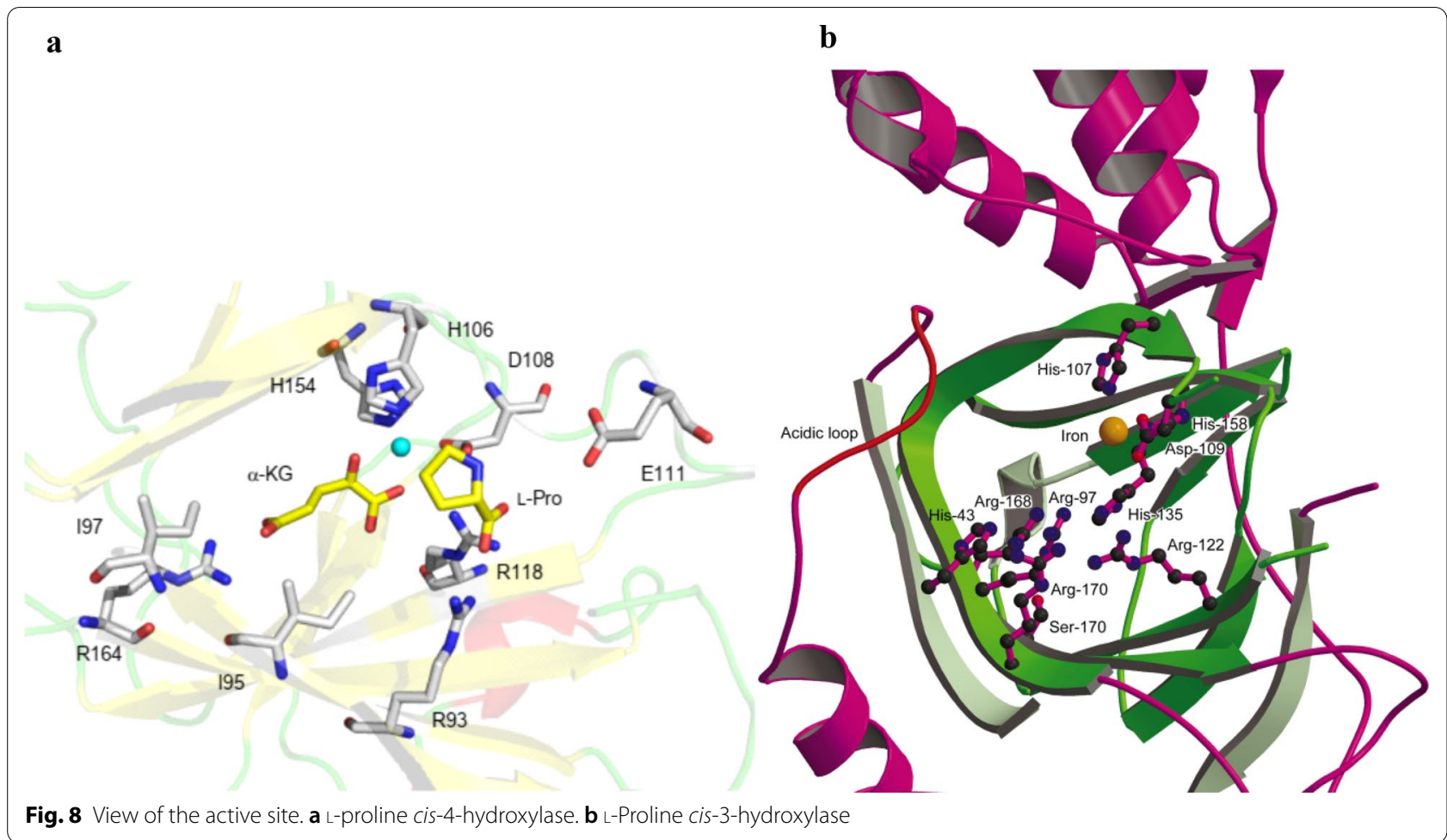

Table 1 Overview of metabolic engineering studies on the production of trans-4-hydroxy-L-proline by microbial cells

\begin{tabular}{|c|c|c|c|c|c|}
\hline Host strain & Expression vectors & Metabolic engineering strategies & Titer $(g / L)$ & Culture system & References \\
\hline E. coli & pTr2-4OH & $\begin{array}{l}\text { (1) }+ \text { Da-p4h }{ }^{\circ} \text {; }(2) \text { promoters }{ }^{\circ} \text { and (3) } \\
\quad \triangle p u t A ;\end{array}$ & 41 & Batch, 5 L (glucose + proline) & [58] \\
\hline E. coli & pSTV29 & $\begin{array}{l}\text { (1) }+ \text { Da-p } 4 h ;(2)+\text { proB }^{*} ;(3)+\text { proA; and } \\
\text { (4) } \triangle \text { putA }\end{array}$ & 25 & Batch, $5 \mathrm{~L}$ (glucose) & [38] \\
\hline E. coli and C. glutamicum & pET28a & $\begin{array}{l}\text { Compared with the Ps-p4h and Bo-p4h, } \\
\text { and Da-p4h }\end{array}$ & 2.28 or 6.72 & $\begin{array}{l}\text { Batch, } 250 \mathrm{~mL} \text { (glucose) or Batch, } \\
250 \mathrm{~mL} \text { (glucose + proline) }\end{array}$ & [19] \\
\hline C. glutamicum & pEKEX2 & $+p 4 h$ & 7.1 & Fed-batch, $3 \mathrm{~L}$ (glucose + isoleucine) & [70] \\
\hline E. coli & pUC19 & $(1)+D a-p 4 h^{\circ} ;(2)$ expression vectors ${ }^{\circ}$; & 25.4 & Fed-batch, 5 L (glycerol + proline) & [81] \\
\hline E. coli & pTrc99a & $(1)+D a-p 4 h ;$ and $(2)+V H b$ & 14.4 & Fed-batch, 1.4 L (glucose + proline) & [75] \\
\hline E. coli & pTrc99a & $\begin{array}{l}\text { (1) + Da-p4h; (2) } \triangle s u c A B ;(3) \triangle a c e A K ;(4) \\
\triangle p u t A ; \text { and (5) + proB*; and (6) + proA } \\
\text { gene }\end{array}$ & 31 & Fed-batch, 5 L (glucose) & {$[67]$} \\
\hline E. coli & pTc & $\begin{array}{l}\text { (1) }+ \text { p4h } h^{g m} ;(2) \Delta p u t A ;(3)+p r o B^{*} ; \text { and } \\
\text { (4) }+ \text { proA }\end{array}$ & 45.83 & Fed-batch, $5 \mathrm{~L}$ (glucose) & [55] \\
\hline C. glutamicum & pXMJ19 & $\begin{array}{l}\text { (1) }+D a-p 4 h ;(2) \triangle s u c C D \text {; and (3) fine- } \\
\text { tuning of pro } B^{*} \text { and } p 4 h \text { abundances }\end{array}$ & 21.72 & Fed-batch, $500 \mathrm{~mL}$ (glucose) & {$[62]$} \\
\hline E. coli & pET21a & $\begin{array}{l}(1)+U n-p 4 h ;(2)+p 4 h^{\mathrm{re}} ;(3) p 4 h^{*} ;(4) \\
\quad \operatorname{putA} ;(5)+\text { proB }^{*} ; \text { and }(6)+\text { proA }\end{array}$ & 12.9 & Fed-batch, 5 L (glucose) & [57] \\
\hline E. coli & pDXW-10 & $\begin{array}{l}\text { (1) }+p 4 h^{r d} ;(2)+p 4 h^{\circ} ;(3) \triangle p u t A ;(4) \\
\quad \Delta p r o P ;(5) \triangle p u t P ;(6) \triangle a c e A ;(7)+p r o B^{*} ; \\
\text { and (8) a tunable circuit based on } \\
\text { quorum sensing }\end{array}$ & 54.8 & Fed-batch, $7.5 \mathrm{~L}$ (glucose) & [69] \\
\hline
\end{tabular}

${ }^{\circ}$ : optimization of the gene codon usage or promoters or expression vectors; ${ }^{\text {gm }}:$ genome mining; ${ }^{\text {re }}$ : replacement of the gene putative “lid" loop; ${ }^{\text {rd }}$ : rational design; + : expression of the gene; $\Delta$ : deletion of the gene; *: mutation of gene; Da: Dactylosporangium sp.RH1; Ps: Pseudomonas stutzeri; Bo: Bordatella bronchiseptica RB50; Un: uncultured bacterium esnapd13 
was optimized by cassette mutagenesis according to the codon usage of $E$. coli genes. The optimized proline 4-hydroxylase gene ligated into the plasmid had 7.7-fold higher activity than the original gene [51]. However, if the codon is only designed to achieve the highest abundance, the tRNAs charged with amino acids that are highly represented may be depleted, and translational errors in the heterologous protein may occur. A special codon optimization strategy that stimulates the relative codon usage of E. coli was proposed to verify that proline 4-hydroxylase production is limited by the charged tRNAs. This method increased proline 4-hydroxylase levels by two to fourfold. Furthermore, because the mRNA levels of the optimized gene generated by the special codon optimization strategy were tenfold higher than those observed for the original gene, the increase in proline 4-hydroxylase synthesis may also have been related to mRNA stability. Another experiment also confirmed that codon usage has a large impact on proline 4-hydroxylase synthesis and that the optimized gene produced higher proline 4-hydroxylase levels in the absence of proline than the original gene in the presence of proline [51]. A high amount of insoluble protein in E. coli may be present when a gene is expressed via commercial vectors. However, in most cases, the active protein tends to be soluble. To obtain much larger amounts of soluble protein, Chen et al. constructed 12 truncated variants of the proline 4-hydroxylase gene by predicting the secondary structure of proline 4-hydroxylase and removing some of the $\mathrm{N}$-terminal or $\mathrm{C}$-terminal amino acids, including the 1-240, 1-257, 1-272, 5-240, 5-257, 5-272, 15-240, 15-257, 15-272, 25-240, 25-257, and 25-272 truncated fragments. Compared with the full-length protein composed of 272 amino acids, the 1-257 truncated fragment generated much more soluble protein and had a higher catalysis efficiency (conversion: $88.97 \%$ in $60 \mathrm{~h}$ ) [52]. The hydroxylase gene used to produce $t 4 \mathrm{Hyp}$ from Dactylosporangium sp. RH1, which has good catalytic activity, can be called $p 4 h D$. However, if used in industrial production, higher activity is required. Thus, hydroxylases need to be improved or new hydroxylases need to be isolated. The $\mathrm{P} 4 \mathrm{H}$ proteins from Pseudomonas stutzeri and Bordetella bronchiseptica $R B 50$, named $p 4 h P$ and $p 4 h B$, respectively, were isolated and characterized, and they were found to exhibit lower catalysis activity than the $p 4 h D$ gene of $\mathrm{P} 4 \mathrm{H}$ [53]. In the past few decades, genome mining has proven to be an effective method to discover new enzymes [54]. Using the genome mining approach to search for new hydroxylases from the GeneBank database, Wang et al. found 3 novel trans-proline-4-hydroxylases from Alteromonas mediterranea (AlP4H), Micromonospora sp. CNB394(MiP4H) and Sorangium cellulosum $(\mathrm{ScP} 4 \mathrm{H})$ from 101 candidates and performed enzymatic determination. AlP4H exhibited the highest $t 4 \mathrm{Hyp}$ production among the trans-proline-4-hydroxylases, including the hydroxylase from Dactylosporangium sp. RH1 [55]. A better understanding of this family of $\alpha$-ketoglutarate-dependent dioxygenases is necessary. The 3D structure of a leucine hydroxylase from Streptomyces DSM 40835 has been characterized, and a loop region (K159-S176) in the leucine hydroxylase covers its active site and plays an important role in substrate binding and access [56]. Compared with the structures of leucine hydroxylase and transproline-4-hydroxylases, replacing the lid loop may alter its enzymatic properties. Liu et al. replaced a new transproline-4-hydroxylase from the uncultured bacterium esnapd13 (UbP4H) putative "lid" loop in combination with site-directed mutagenesis to enhance hydroxylase activity and thermos-stability [57].

\section{Optimization of expression elements}

To improve $t 4$ Hyp production by regulating the expression levels of the genes and harmonizing the metabolic pathways in the host system, optimization of expression elements is required. The trp, trp tandem, and tac promoters were evaluated. Among them, the trp tandem promoter showed higher activity than the other promoters [58]. Regarding vectors, pET-M-3C containing a His fusion tag and the T7 promoter, $\mathrm{pET}-32 \mathrm{M}-3 \mathrm{C}$ containing a Trx-His fusion tag and the T7 promoter, pUC18 containing no fusion tag and the lac promoter, and pTTQ18 containing no fusion tag and the tac promoter were evaluated. pET-M-3C showed a higher substrate conversion efficiency (conversion: $76.60 \%$ in $60 \mathrm{~h}$ ) than the other vectors [52]. These results suggest that the expression system exerted an obvious effect on enzyme activity and $t 4 \mathrm{Hyp}$ production. An important process is the regulation of the initial translation rate of the protein and determination of its protein abundance, which involves the interactions of ribosomes with the $5^{\prime}$ untranslated regions and mRNA folding energetics. To accelerate protein synthesis and increase protein abundance, the rate of ribosome binding to mRNA should be faster than that of the refolding of mRNA [59, 60]. The ribosome binding site (RBS) can be optimized using the software RBS Calculator v2.0 to achieve the maximum translation initiation rate [61]. The optimized RBS and $p 4 h$ gene should be co-expressed in an engineered strain. As expected, the abundance of $\mathrm{P} 4 \mathrm{H}$ was higher than that of the original gene, and the new strain produced up to $8.47 \mathrm{~g} / \mathrm{L}$ of $t 4 \mathrm{Hyp}$, which was increased by $76 \%$ compared with that in the original strain. Moreover, the maximal specific $\mathrm{P} 4 \mathrm{H}$ activity and productivity also increased by $67 \%$ and $68 \%$, respectively [62]. The same result was observed because the optimization of the RBS strength improved the balance of $t 4 \mathrm{Hyp}$ 
production and cell growth to benefit and enhance $t 4 \mathrm{Hyp}$ productivity [63].

\section{Deletion of the proline degradation pathway}

As mentioned above, proline can be degraded into glutamate via the PutA protein. To examine the effect of proline metabolism and its regulation on proline hydroxylation, how the putA gene affects t4hyp synthesis should be investigated. Shibasaki et al. deleted the putA gene of $E$. coli to block the pathway from proline to glutamate and increased the yield of $t 4 \mathrm{Hyp}$ from proline (87 to 100\%) [58]. Additionally, the concentration of glutamate was decreased when the putA gene was deleted, while $t 4$ Hyp production and its conversion rate were increased by $35.0 \%$, up to $41.3 \mathrm{~g} / \mathrm{L}$ and $72.5 \%$, respectively [63]. Although the $\triangle p u t A$ strain could not degrade proline, reducing energy consumption in response to low glucose uptake rates to offset the loss of ATP and NADH did not increase TCA activity [64]. These results suggest that proline degradation is one of the limited factors affecting $t 4 \mathrm{Hyp}$ production and that the deletion of the proline degradation pathway is a promising strategy to improve the hydroxylation efficiency.

\section{Regulation of proline availability}

In the proline biosynthetic pathway, proline synthesis from glutamate is sequentially catalyzed by $\operatorname{pro} B$ (encoding $\gamma$-glutamyl kinase), $\operatorname{pro} A$ (encoding $\gamma$-glutamyl phosphate reductase) and proC (encoding pyrroline-5carboxylate reductase). The regulatory mechanism of the proline biosynthetic pathway is the feedback inhibition of ProB by proline. ProB74, a ProB mutant, showed a 360-fold lower sensitivity to feedback inhibition by proline [20]. When ProB74 was used to produce $t 4$ Hyp, the productivity was much higher than that of ProB $[38,65]$. Considering that L-proline is an important precursor of $t 4 \mathrm{Hyp}$ and may be a limiting factor for $t 4 \mathrm{Hyp}$ production, the availability of L-proline for hydroxylation should be regulated. Given that the gene expression levels of the proB 74 and $p 4 h$ genes might affect the proline formation and proline hydroxylation rates, Zhang et al. designed two expression cassettes, Ptac-p4h-proB74 and PtacproB74-p4h, as well as an optimized RBS and universal RBS that were separately used to control the protein levels of the proB74 and $p 4 h$ genes. A higher translation initiation rate of proB74 contributed to an increase in carbon flux for proline synthesis. However, with the same translation initiation rate of proline 4-hydroxylase, only a low protein level of ProB74 improves the conversion efficiency from proline to $t 4 \mathrm{Hyp}$, and the engineered strain produces up to $21.72 \mathrm{~g} / \mathrm{L} t 4 \mathrm{Hyp}$ with a yield of $0.27 \mathrm{~mol} /$ mol and a productivity of $0.36 \mathrm{~g} / \mathrm{L} / \mathrm{h}[62]$. From the above data, a higher translation initiation rate of hydroxylase combined with a lower protein level of feedback-resistant $\gamma$-glutamyl kinase contributes to increasing the hydroxylation efficiency.

\section{Reconstruction of the tricarboxylic acid cycle (TCA) and glyoxylate pathway}

The TCA cycle is a key metabolic pathway that connects carbohydrate, fat, and protein metabolism. Because $a$-ketoglutarate $(\alpha-K G)$ serves as an intermediate of the TCA cycle and hydroxylases, the availability of $\alpha-K G$ has an important effect on $t 4 \mathrm{Hyp}$ production, while proline hydroxylases can convert cosubstrates (including $\alpha-K G$ ) to succinate. Thus, cell growth competes with proline hydroxylation. Additionally, $\alpha-K G$ can be shunted for glyoxylate synthesis. To force and improve $\alpha-K G$ flux to the proline hydroxylation reaction, reconstruction of the TCA cycle and glyoxylate pathway should be performed. The TCA cycle involves several key metabolic genes, such as $\operatorname{sucAB}$, which encodes $\alpha$-ketoglutarate dehydrogenase, and sucCD, which encodes sucCoA synthetase [65]. In the glyoxylate pathway, aceA encodes isocitrate lyase (AceA) and aceK encodes isocitrate dehydrogenase kinase/phosphatase (AceK). The influence of the modification strategy on $t 4$ Hyp production depends on which genes should be modified. When evaluating the influence of $\alpha-K G$ dehydrogenase or sucCoA synthetase deletion on host physiology, the SucA ( $\alpha$-KG dehydrogenase E1 subunit) and sucC (sucCoA synthetase $\beta$ subunit) genes were alternately deleted in combination with aceA and putA. Severe impairment of sucCoA synthesis was observed; for example, the triple mutant strain $3 \Delta s u c A(\Delta s u c A \triangle a c e A \Delta p u t A)$ could not grow in minimal medium; however, the introduction of proline 4-hydroxylase utilizing proline hydroxylation as a TCA cycle bypass restored growth, causing a lower growth rate, final biomass concentration, and average cell size than those of the wild-type strain due to the decreased sucCoA pool and deficiency of the glyoxylate pathway. By contrast, no obvious effect was observed for the triple mutant strain $3 \Delta \operatorname{sucC}(\Delta s u c C \Delta a c e A \Delta p u t A)$, which could grow in minimal medium. These results indicate that the $s u c C$ deletion strain obtained sucCoA from $\alpha-K G$ via $\alpha-K G$ dehydrogenase [66]. Similar results were observed because the deletion of sucAB and aceAK in E. coli inhibits the pathways of succinate biosynthesis, glyoxylate, and IDH phosphorylation, which contribute to coupling L-proline hydroxylation with strain growth. Thus, the modified strain exhibited higher conversion of L-proline and a higher yield of $t 4 \mathrm{Hyp}$ [67]. To improve $t 4 \mathrm{Hyp}$ production, a genome-scale metabolic network model was applied to identify potential targets. Zhang et al. set $t 4$ Hyp production as the maximal object, and the biomass and flux via $\alpha$-ketoglutarate dehydrogenase and succinyl-CoA 
synthetase dropped to zero. However, when the biomass was set as the maximal object, zero flux via succinyl-CoA synthetase and low flux via $\alpha$-ketoglutarate dehydrogenase increased $t 4$ Hyp production. Thus, these in silico simulation results indicate that the deletion of sucCD genes encoding succinyl-CoA synthetase may improve $t 4$ Hyp production. Consequently, the $\triangle s u c C D$ strain produced $4.81 \mathrm{~g} / \mathrm{L}$ of trans-4-hydroxy-L-proline, $60 \%$ higher than the amount produced by the wild-type strain. Furthermore, the yield of trans-4-hydroxy-L-proline on glucose increased by $50 \%$ [62]. This finding was confirmed by simultaneously deleting the $s u c C$ and $s u c D$ genes in E. coli; the resulting strain, E. coli $\triangle$ sucCD, showed a $139.1 \%$ increase in $t 4$ Hyp production up to $30.6 \mathrm{~g} / \mathrm{L}$ without $\alpha-K G$ addition compared with that of the wildtype strain [63]. In Corynebacterium glutamicum, the activity of the $\alpha$-ketoglutarate dehydrogenase complex (ODHC) can be dynamically modulated by L-isoleucineresponsive transcription or attenuation strategies [68]. A similar strategy was adopted to regulate ODHC activity in E. coli, in which a tunable circuit based on quorum sensing was used to improve the flux of $\alpha-K G$ by twisting the flow between the TCA cycle and $t 4 \mathrm{Hyp}$ production; this approach also showed better performance than that achieved by directly deleting sucA [69].

\section{Improvement of oxygen transfer}

Given the catalytic characteristics of proline hydroxylase, large amounts of oxygen are required for $t 4$ Hyp production [42]. During fermentation, the soluble protein or other substance secreted by the strain will cause the fermentation broth to possess a high viscosity, which interferes with oxygen transfer and decreases the dissolved oxygen levels. Thus, the oxygen supply is usually considered a rate-limiting factor for $t 4$ Hyp production [70]. To solve this problem, several strategies may be attempted: (1) increasing the agitation, aeration rates, and pressure of the bioreactor, (2) introducing the Vitreoscilla hemoglobin gene $(v g b)$, or (3) adding a protease. However, increasing the agitation and aeration rates may cause extensive energy consumption and physical damage to the cells [71]. Bacterial hemoglobin ( $\mathrm{VHb}$ ) is necessary for Vitreoscilla, a strict aerobic bacterium, to survive in an oxygen-poor environment [72]. In high-cell-density fermentation processes, the presence of $\mathrm{VHb}$ enhances ATP production and energy metabolism by promoting oxygen transfer under $\mathrm{O}_{2}$-limited conditions, which has been widely used to improve the growth and production of target products [73, 74]. Zhao et al. integrated the Vitreoscilla hemoglobin gene $(v g b)$ into the chromosome of recombinant $E$. coli to increase $t 4 \mathrm{Hyp}$ production. In a shaking flask culture, the strain expressing Vitreoscilla hemoglobin $(\mathrm{VHb})$ produced $8.23 \mathrm{~g} / \mathrm{L}$ of $t 4 \mathrm{Hyp}$, which was approximately a 1.9-fold increase over that of the strain not expressing VHb $(4.24 \mathrm{~g} / \mathrm{L})$ [75]. Additionally, in a 5 - $\mathrm{L}$ fermenter, $t 4 \mathrm{Hyp}$ production $(48.8 \mathrm{~g} / \mathrm{L})$ was increased by $2.5 \%$ than that in the absence of $\mathrm{VHb}$ overexpression, and the productivity $(1.02 \mathrm{~g} / \mathrm{L} / \mathrm{h})$ was increased by $54.5 \%$ [63].

\section{Trans-4-hydroxy-L-proline production in Corynebacterium glutamicum}

To date, research on $t 4 \mathrm{Hyp}$ production has mainly focused on E. coli. However, Corynebacterium glutamicum, a nonpathogenic, Gram-positive bacterium, which is a popular industrial microorganism and is usually applied in amino acid, vitamin and nucleic acid production, should be introduced for $t 4 \mathrm{Hyp}$ production [76]. In 1957, this bacterium was first discovered for its excellent ability to produce abundant L-glutamate [77]. C. glutamicum has been studied thoroughly for its amino acid production, and several molecular tools for metabolic network operation that benefit C. glutamicum as an important host system have been developed [78, 79]. The availability of intracellular proline may be limited because the biosynthesis of proline in E. coli is strictly regulated to a low level and the high $\mathrm{L}$-proline production in C. glutamicum makes C. glutamicum a better candidate for $t 4$ Hyp production [80]. A novel strategy applies recombinant $C$. glutamicum strains to produce $t 4 \mathrm{Hyp}$, and the differences between $C$. glutamicum and E. coli as hosts for $t 4$ Hyp production are observed when the hydroxylase genes from diverse resources are cloned and expressed simultaneously. Microbial systems for $t 4 \mathrm{Hyp}$ production have been constructed by introducing proline 4-hydroxylase into C. glutamicum and E. coli. Although both recombinant $C$. glutamicum and $E$. coli strains can produce $t 4 \mathrm{Hyp}$, a higher yield $(0.47 \mathrm{~g} / \mathrm{L})$ was observed in recombinant $E$. coli than in C. glutamicum [53]. To produce $t 4$ Hyp from glucose in minimal medium, Falcioni et al. introduced the proline 4-hydroxylase gene into an isoleucine-deficient C. glutamicum strain. The effects of various glucose/isoleucine molar ratios on $t 4 \mathrm{Hyp}$ production were observed, and a molar ratio of $46: 1$ was found to maximize $t 4 \mathrm{Hyp}$ production $(0.2 \mathrm{~g} / \mathrm{L})$ [70]. Zhang et al. engineered C. glutamicum by reconstructing the TCA cycle, expressing the proline 4-hydroxylase gene and fine-tuning the abundances of plasmid-borne feedback-resistant $\gamma$-glutamyl kinase and proline 4-hydroxylase for the fermentative production of $t 4 \mathrm{Hyp}$, achieving the highest titer $(21.72 \mathrm{~g} / \mathrm{L})$ in glucose-minimal medium [62]. Although a large amount of $t 4$ Hyp production in $C$. glutamicum was not efficiently synthesized, it remains challenging to develop t4Hyp-producing C. glutamicum with excellent fermentation performance considering the characteristics of high proline production. 


\section{Metabolic engineering of trans-4-hydroxy-L-proline production in a bioreactor}

To examine the real ability of $t 4 \mathrm{Hyp}$ production, the conditions it is must be observed during cultivation in a bioreactor. The culture conditions $(\mathrm{pH}$, temperature, agitation of the jar fermenter, induction time, and bioreactor type) significantly affect microbial $t 4$ Hyp production. The $\mathrm{pH}$ and temperature used for $t 4 \mathrm{Hyp}$ production by E. coli are usually $6.0-7.0$ and $30-37^{\circ} \mathrm{C}$, respectively. In addition to temperature and $\mathrm{pH}$, the initial concentration of L-proline and agitation of the jar fermenter also needed optimization. Combined with optimized promoters and deletion of the $p u t A$ gene, $t 4 \mathrm{Hyp}$ can accumulate to a concentration of $41 \mathrm{~g} / \mathrm{L}$ (100\% yield from L-proline) in $100 \mathrm{~h}$ when the cells are cultivated in medium containing glucose and $\mathrm{Fe}^{2+}$ [58]. T4Hyp can be produced in fermentation broth by supplementing the necessary substrate or utilizing harvested cells to induce L-proline hydroxylation in a reaction system. The maintenance of $\mathrm{pH}$ is required during this process. Additionally, a feeding strategy usually improves the production of the product. The fermentative production of $t 4 \mathrm{Hyp}$ can be divided into two types based on the addition of proline to the fermentative medium. The addition of proline can increase $t 4$ Hyp production, but it also increases the cost. Achieving a high titer and $t 4 \mathrm{Hyp}$ production without proline addition is attractive. The first reported method to produce $t 4$ Hyp by fermentation in a 5 - $\mathrm{L}$ jar fermenter did not involve proline addition through the expression of proline 4-hydroxylase from Dactylosporangium sp. RH1, feedback resistant $\gamma$-glutamyl kinase (ProB74), or glutamate$\gamma$-semialdehyde dehydrogenase (ProA) combined with the deletion of PutA engineered E. coli, and this method achieved $25 \mathrm{~g} / \mathrm{L}$ of $t 4 \mathrm{Hyp}$ after $96 \mathrm{~h}$ of cultivation [38]. Although fermentative production of $t 4 \mathrm{Hyp}$ has been achieved, the long culture time required and low titer produced limit its industrial application. In E. coli, Zhang et al. overexpressed hydroxylase $(\mathrm{P} 4 \mathrm{H}), \gamma$-glutamyl kinase and glutamate-semialdehyde dehydrogenase (ProBA) and knocked out putA, which encodes proline dehydrogenase (PutA), sucAB, which encodes $\alpha$-ketoglutarate dehydrogenase (SucAB), aceAK, which encodes isocitrate lyase(AceA), and isocitrate dehydrogenase kinase/phosphatase (AceK) in the TCA cycle, resulting in $31.0 \mathrm{~g} / \mathrm{L}$ of $t 4$ Hyp obtained directly from glucose after $52 \mathrm{~h}$ of fermentation in a 5-L fermenter; thus, this method reduced the culture time and increased the titer [67]. In a fedbatch fermentation with a 5-L bioreactor without proline addition, Wang et al. accumulated $45.83 \mathrm{~g} / \mathrm{L}$ of $t 4 \mathrm{Hyp}$ within $36 \mathrm{~h}$ by introducing a new proline 4-hydroxylase from Alteromonas mediterranea $(\mathrm{AlP} 4 \mathrm{H})$, which was discovered through genome mining a putA-deficient $E$. coli strain expressing the proB74 and proA genes [55].
To examine $t 4$ Hyp production by proline 4-hydroxylase via loop grafting and site-directed mutagenesis, a $t 4 \mathrm{Hyp}-$ producing strain was constructed, as previously reported [55]. After introducing the evolutive proline 4-hydroxylase, a fed-batch fermentation in a 5 -L bioreactor at $37^{\circ} \mathrm{C}$ using glucose as the sole carbon source without proline addition was performed. Although only $12.9 \mathrm{~g} / \mathrm{L}$ of $t 4 \mathrm{Hyp}$ was obtained, this concentration was 3.3-fold higher than that produced by the wild-type proline 4-hydroxylase control and simultaneously improved the activity and thermostability [57]. The highest $t 4 \mathrm{Hyp}$ production to date was $54.8 \mathrm{~g} / \mathrm{L}$ at $60 \mathrm{~h}$ using integrated system engineering in $E$. coli without L-proline addition in a $7.5-\mathrm{L}$ bioreactor, in which the deletion of putA, proP, putP, and $a c e A$, and the mutation of proB contributed to L-proline and relieved its feedback inhibition, and a tunable circuit based on quorum sensing for the dynamic regulation of ODHC activity and rationally designed L-proline hydroxylase [69]. t4Hyp production using proline 4-hydroxylase with chemo-physical combination mutagenesis, taking glycerol as the carbon source, and optimizing the fermentation medium(tryptone, $\mathrm{FeSO}_{4}$, L-proline) with singlefactor, Plackett-Burman, steepest ascent, and a central composite design experiment, was achieved at $25.4 \mathrm{~g} / \mathrm{L}$ of $t 4 \mathrm{Hyp}$ [81]. Subsequently, Zhao et al. attained a $t 4 \mathrm{Hyp}$ concentration of $14.4 \mathrm{~g} / \mathrm{L}$ by integrating the Vitreoscilla hemoglobin gene $(v g b)$ into recombinant $E$. coli expressing proline 4-hydroxylase in fed-batch fermentation in a 1.4-L bioreactor after $57 \mathrm{~h}$ of cultivation [75]. T4Hyp production from glucose in minimal media by Corynebacterium glutamicum has also been reported. Although proline was not added, isoleucine supplementation was necessary because the effect of various glucose/isoleucine molar ratios on $t 4$ Hyp production was observed. Highcell-density fed-batch fermentation in a 3-L KLF reactor was performed and produced $7.1 \mathrm{~g} / \mathrm{L}$ of $t 4 \mathrm{Hyp}$ from glucose at $23 \mathrm{~h}$ by introducing proline 4-hydroxylase from the Dactylosporangium sp. strain RH1 into isoleucinedeficient (leaky auxotroph) C. glutamicum at a glucose/ isoleucine molar ratio of 46:1[70].

\section{Perspectives}

Currently, the construction of microbial cell factories for amino acid production is a promising strategy. Metabolic engineering involves improving the development of microbial strains to produce various chemicals by modification of enzymes, transporters, and metabolic pathways. Thus, $t 4$ Hyp can be produced on a large scale. In the past few years, $t 4$ Hyp production by engineered $E$. coli has been significantly improved by metabolic engineering. Overexpression of the endogenous pathways for $t 4 \mathrm{Hyp}$ biosynthesis or heterologous genes and elimination of competing pathways, combined with evolutive proline 
hydroxylases, has enabled engineered $E$. coli to produce over $50 \mathrm{~g} / \mathrm{L}$ of $t 4 \mathrm{Hyp}$. Considering that the culture time must be shortened, the cost must be reduced, and $t 4 \mathrm{Hyp}$ production must be improved for industrial application, much more work is needed.

\section{The key factors in $\mathbf{t 4 H y p}$ production are proline hydroxylases}

Although thousands of microorganisms have been screened, few proline hydroxylases with high enzyme activity have been identified. Thus, it is necessary to identify more microorganisms that can produce $t 4 \mathrm{Hyp}$ in nature. However, screening is time-consuming and laborintensive. As reviewed in this paper, overcoming the problem using tools such as genome mining or directed evolution of proline hydroxylases is also a promising strategy to improve activity and stability. The new proline hydroxylases obtained using a de novo enzyme design and computational models may not be comparable with natural proline hydroxylases, but the predicted structure of proline hydroxylases contribute to our understanding of the properties of hydroxylases.

\section{Regulation of the host cell metabolic network is also important for $\mathbf{t 4 H y p}$ production}

The microbial metabolic network is so large and complex that it is difficult to determine which genes need to be modified. Metabolic simulation using a genome-scale metabolic model or ${ }^{13} \mathrm{C}$ metabolic flux analysis can help determine the metabolic network and rational design that are already applied to produce $t 4 \mathrm{Hyp}$ [82]. Genome modification approaches such as gene knockout might not be the best methods for blocking some biosynthetic pathways, and downregulating gene expression might be a much better strategy. CRISPR interference (CRISPRi) is a useful technique to reduce the transcription of target genes with up to 1000 -fold repression. This modified system achieved an RNA-guided DNA recognition platform by coexpressing a modified Cas9 protein (lacking endonucleolytic activity) with an sgRNA designed (20 bp) a complementary region that yields specific silencing of a gene of interest without off-target effects [83]. This CRISPRi technology was employed to repress the expression of the putA gene in E. coli for cis-4-hydroxy-L-proline production, and the yield was increased [84].

In addition to $t 4 \mathrm{Hyp}$, much progress in improving the production of many other amino acids in engineered strains has been made by applying these strategies. By fully elucidating the $t 4 \mathrm{Hyp}$ biosynthetic pathway, these strategies and the conception of new ideas should allow improvements in $t 4 \mathrm{Hyp}$ production by metabolic engineering.

\section{Abbreviations}

t4Hyp: Trans-4-Hydroxy-L-proline; E. coli: Escherichia coli; C. glutamicum: Corynebacterium glutamicum; TCA cycle: Tricarboxylic acid cycle; ATP: Adenosine triphosphate; FAD: Flavin adenine dinucleotide; NADH: Reduced form of nicotinamide-adenine dinucleotide; EDTA: Ethylene diamine tetraacetic acid; SDS-PAGE: Sodium dodecyl sulfate-polyacrylamide gel electrophoresis; CRISPRi: CRISPR interference; IPTG: Isopropyl $\beta$-D-thiogalactoside; RBS: Ribosome binding site; a-KG: a-Ketoglutarate.

\section{Acknowledgements \\ Not applicable.}

\section{Authors' contributions}

ZYZ and PFL conceived and wrote the manuscript. $\mathrm{XHC}$ revised the manuscript. All of the other authors contributed to the background research. All authors read and approved the final manuscript.

Funding

This work was supported by the National Key Research and Development Program of China (2018YFC0311004).

\section{Availability of data and materials}

All the data generated or analyzed during this review are included in published article.

\section{Declarations}

Ethics approval and consent to participate

Not applicable.

\section{Consent for publication}

Not applicable.

\section{Competing interests}

The authors declare that they have no competing interests.

\section{Author details}

${ }^{1}$ Collaborative Innovation Center of Yangtze River Delta Region Green Pharmaceuticals, Zhejiang University of Technology, Hangzhou 310014, Zhejiang, People's Republic of China. ${ }^{2}$ School of Pharmaceutical Sciences, Zhejiang University of Technology, Hangzhou 310014, Zhejiang, People's Republic of China.

Received: 12 October 2020 Accepted: 13 April 2021

Published online: 21 April 2021

\section{References}

1. Krane SM. The importance of proline residues in the structure, stability and susceptibility to proteolytic degradation of collagens. Amino Acids. 2008:35:703-10.

2. Phang JM, Donald SP, Pandhare J, Liu Y. The metabolism of proline, a stress substrate, modulates carcinogenic pathways. Amino Acids. 2008;35:681-90.

3. Phang JM, Wei L, Zabirnyk O. Proline metabolism and microenvironmental stress. Annu Rev Nutr. 2010;30:441.

4. Ananthanarayanan VS. Structural aspects of hydroxyproline-containing proteins. J Biomol Struct Dyn. 1983;1:843-55.

5. Aro E, Salo AM, Khatri R, Finnila M, Miinalainen I, Sormunen R, Pakkanen O, Holster T, Soininen R, Prein C, et al. Severe extracellular matrix abnormalities and chondrodysplasia in mice lacking collagen prolyl 4-hydroxylase isoenzyme II in combination with a reduced amount of isoenzyme I. J Biol Chem. 2015;290:16964-78.

6. Gorres KL, Raines RT. Prolyl 4-hydroxylase. Crit Rev Biochem Mol Biol. 2010;45:106-24.

7. Wichmann CF, Liesch JM, Schwartz RE. L-671,329, a new antifungal agent. II. Structure determination. J Antibiot. 1989;42:168.

8. Remuzon P. Trans-4-hydroxy-L-proline, a useful and versatile chiral starting block. Tetrahedron. 1996;52:13803-35. 
9. Baldwin JE, Pritchard GJ, Williamson DS. The synthesis of 4-arylsulfanylsubstituted kainoid analogues from trans -4-hydroxy- I -proline. Chemlnform. 2000;31:7991-7.

10. Jung JC, Avery MA. Diastereoselective synthesis of $(2 S, 5 S)$ - and $(2 S, 5 R$ )- $\mathrm{N}$-benzyloxycarbonyl-5-hydroxypipecolic acids from trans -4-hydroxy- 1 -proline. Tetrahedron Asymmetry. 2006;17:2479-86.

11. Wen Y, Gao B, Fu Y. Chemlnform Abstract: asymmetric three-component strecker reactions catalyzed by trans-4-Hydroxy-L-proline-Derived N, $\mathrm{N}^{\prime}$ Dioxides. Chemistry. 2008;14(22):6789-95.

12. Sugimura Y, Shibata T, lino K. synthesis of optically active 3-mercaptopyrrolidine derivatives. Synthetic intermediates of carbapenem RS533 and its isomer. Heterocycles. 1986;24:1331.

13. Giuseppe C, Piero DC, Francesco F, Concetta LR. Enantiomerically pure polyheterocyclic spiro-beta-lactams from trans-4-hydroxy-L-proline. J Org Chem. 2010;75:2010-7.

14. Reddy VP, Kumar AV, Rao KR. New strategy for the synthesis of -aryl pyrroles: Cu-catalyzed C-N cross-coupling reaction of -proline with aryl halides. ChemInform. 2011;52:777-80.

15. Kumar AV, Rao KR. ChemInform Abstract: trans-4-hydroxy-L-proline: a novel starting material for $\mathrm{N}$-alkylpyrroles synthesis. Tetrahedron Lett. 2011;52:3237-9.

16. Hoa BTM, Takao H, Ryo N, Goh M, Yu S, Hiroshi T. Production of N-acetyl cis-4-hydroxy-L-proline by the yeast N-acetyltransferase Mpr 1. J Biosci Bioeng. 2012;114:160-5.

17. Kanasty RL, Vegas AJ, Ceo LM, Maier M, Charisse K, Nair JK, Langer $\mathrm{R}$, Anderson DG. Sequence-defined oligomers from hydroxyproline building blocks for parallel synthesis applications. Angew Chem Int Ed. 2016;128:9681-5.

18. Cao G, Yang K, Li Y, Huang L, Teng D. Synthetic strategy and anti-tumor activities of macrocyclic scaffolds based on 4-hydroxyproline. Molecules. 2016;21:212.

19. Yi Y, Sheng H, Li Z, Ye Q. Biosynthesis of trans- 4-hydroxyproline by recombinant strains of Corynebacterium glutamicum and Escherichia coli. BMC Biotechnol. 2014;14:44.

20. Smith LT. Characterization of a gamma-glutamyl kinase from Escherichia coli that confers proline overproduction and osmotic tolerance. J Bacteriol. 1985;164:1088.

21. Baich A. Proline synthesis in Escherichia coli a proline-inhibitable glutamic acid kinase. BBA General Subjects. 1969;192:462-7.

22. Isabel PA, Vicente R, Javier C. Dissection of Escherichia coli glutamate 5-kinase: functional impact of the deletion of the PUA domain. FEBS Lett. 2005:579:6903-8.

23. Baich A. The biosynthesis of proline in Escherichia coli: phosphatedependent glutamate-semialdehyde dehydrogenase (NADP), the second enzyme in the pathway. BBA General Subjects. 1971;244:129-34.

24. Hayzer DJ, Moses V. The enzymes of proline biosynthesis in Escherichia coli. Their molecular weights and the problem of enzyme aggregation. Biochem J. 1978;173:219.

25. Smith CJ, Deutch AH, Rushlow KE. Purification and characteristics of a gamma-glutamyl kinase involved in Escherichia coli proline biosynthesis. J Bacteriol. 1984;157:545-51.

26. Rossi JJ, Vender J, Berg CM, Coleman WH. Partial purification and some properties of delta1-pyrroline-5-carboxylate reductase from Escherichia coli. J Bacteriol. 1977;129:108-14.

27. Brown $E D$, Wood JM. Redesigned purification yields a fully functional PutA protein dimer from Escherichia coli. J Biol Chem. 1992;267:13086-92.

28. Spicer P. Ostrovsky De, Maloy S, PutA protein, a membrane-associated flavin dehydrogenase, acts as a redox-dependent transcriptional regulator. Proc Natl Acad Sci USA. 1993;90:4295-8.

29. Nadaraia S, Lee YH, Becker DF, Tanner JJ. Crystallization and preliminary crystallographic analysis of the proline dehydrogenase domain of the multifunctional PutA flavoprotein from Escherichia coli. Acta Crystallogr A. 2010;57:1925-7.

30. Maloy SR, Roth JR. Regulation of proline utilization in Salmonella typhimurium: characterization of put: Mu d(Ap, lac) operon fusions. J Bacteriol. 1983;154:561-8.

31. Muro-Pastor AM, Ostrovsky P, Maloy S. Regulation of gene expression by repressor localization: biochemical evidence that membrane and DNA binding by the PutA protein are mutually exclusive. J Bacteriol. 1997;179:2788.
32. Ostrovsky DSP, O'brien K, Maloy S. Regulation of proline utilization in Salmonella typhimurium: a membrane-associated dehydrogenase binds DNA in vitro. J Bacteriol. 1991;173:211-9.

33. Kuttan R, Radhakrishnan AN. Biochemistry of the hydroxyprolines. Adv Enzymol Relat Areas Mol Biol. 1973;37:273.

34. Epstein AC, Gleadle JM, McNeill LA, Hewitson KS, O'Rourke J, Mole DR, Mukherji M, Metzen E, Wilson MI, Dhanda A, et al. C. elegans EGL-9 and mammalian homologs define a family of dioxygenases that regulate HIF by prolyl hydroxylation. Cell. 2001;107:43-54.

35. Acker T, Fandrey J, Helmut H. The good, the bad and the ugly in oxygensensing: ROS, cytochromes and prolyl-hydroxylases. Cardiovasc Res. 2006;71:195-207.

36. Hirsilä M, Koivunen P, Günzler V, Kivirikko KI, Myllyharju J. Characterization of the human prolyl 4-hydroxylases that modify the hypoxia-inducible factor. J Biol Chem. 2003;278:30772-80.

37. Onishi M. Proline hydroxylation by cell free extract of a streptomycete. Biochem Biophys Res Commun. 1984;120:45-51.

38. Shibasaki T, Hashimoto S, Mori H, Ozaki A. Construction of a novel hydroxyproline-producing recombinant Escherichia coli by introducing a proline 4-hydroxylase gene. J Biosci Bioeng. 2000;90:522-5.

39. Hausinger RP. Fe(II)/a-ketoglutarate-dependent hydroxylases and related enzymes. Crit Rev Biochem Mol Biol. 2004;39:48.

40. Zhao J, Liu C, Guo X, Wang J, Liu H, Zheng P, Sun J, Ma Y. Efficient production of trans-3-hydroxyproline by a bacterial trans-3-proline hydroxylase and characterization of enzymatic properties. Biochem Eng J. 2019;147:57-61.

41. Petersen L, Olewinski R, Salmon P, Connors N. Novel proline hydroxylase activities in the pneumocandin-producing fungus Glarea lozoyensis responsible for the formation of trans 3- and trans 4-hydroxyproline. Appl Microbiol Biotechnol. 2003;62:263-7.

42. Shibasaki T, Mori H, Chiba S, Ozaki A. Microbial proline 4-hydroxylase screening and gene cloning. Appl Environ Microbiol. 1999;65:4028-31.

43. Mori H, Shibasaki T, Yano K, Ozaki A. Purification and cloning of a proline 3-hydroxylase, a novel enzyme which hydroxylates free L-proline to cis3-hydroxy-L-proline. J Bacteriol. 1997;179:5677-83.

44. Hara R, Kino K. Characterization of novel 2-oxoglutarate dependent dioxygenases converting I-proline to cis-4-hydroxy-l-proline. Biochem Biophys Res Commun. 2009:379:882-6.

45. Koketsu K, Shomura Y, Moriwaki K, Hayashi M, Mitsuhashi S, Hara R, Kino K, Higuchi Y. Refined regio- and stereoselective hydroxylation of I-pipecolic acid by protein engineering of I-proline cis-4-hydroxylase based on the X-ray crystal structure. ACS Synth Biol. 2014;4:383-92.

46. Shibasaki T, Sakurai W, Hasegawa A, Uosaki Y, Mori H, Yoshida M, Ozaki A. Substrate selectivities of proline hydroxylases. Tetrahedron Lett. 1999:40:5227-30

47. Blanchard JS, Englard S, Kondo A. y-Butyrobetaine hydroxylase: a unique protective effect of catalase. Arch Biochem Biophys. 1982;219:327-34.

48. Nietfeld JJ, Kemp A. The function of ascorbate with respect to prolyl 4-hydroxylase activity. Biochim Biophys Acta. 1981;657:159-67.

49. Lawrence CC, Sobey WJ, Field RA, Baldwin JE, Schofield CJ. Purification and initial characterization of proline 4-hydroxylase from Streptomyces griseoviridus P8648: a 2-oxoacid, ferrous-dependent dioxygenase involved in etamycin biosynthesis. Biochem J. 1996;313(Pt 1):185-91.

50. Mehlführer M, Berner $H$, Thirring K. A short stereoselective synthesis of cis- and trans-4-hydroxyl-L-proline. J Chem Soc. 1994. https://doi.org/10. 1039/C39940001291.

51. Shibasaki T, Mori H, Ozaki A. Enzymatic production of trans-4-hydroxy$\mathrm{L}$-proline by regio- and stereospecific hydroxylation of L-proline. Biosci Biotechnol Biochem. 2000;64:746-50.

52. Chen J, Gu D, LiT, Ju J, Xue Z, Li C, Yan J, Zhang J, Wang L-A. An efficient procedure for the production of trans-4-hydroxy-L-proline using recombinantly expressed proline hydroxylase. Sci Iran. 2015;22:2350-7.

53. Yi Y, Sheng H, Li Z, Ye Q. Biosynthesis oftrans-4-hydroxyproline by recombinant strains of Corynebacterium glutamicum and Escherichia coli. BMC Biotechnol. 2014;14:44.

54. Wang S, Jiao Y, Fang Y, Liu S. Discovery a novel organic solvent tolerant esterase from Salinispora arenicola CNP193 through genome mining. Int J Biol Macromol. 2015;80:334-40.

55. Wang XC, Liu J, Zhao J, Ni XM, Zheng P, Guo X, Sun CM, Sun JB, Ma YH Efficient production of trans-4-hydroxy-l-proline from glucose using 
a new trans-proline 4-hydroxylase in Escherichia coli. J Biosci Bioeng 2018;126:470-7.

56. Lukat P, Katsuyama Y, Wenzel S, Binz T, König C, Blankenfeldt W, Brönstrup M, Müller R. Biosynthesis of methyl-proline containing griselimycins, natural products with anti-tuberculosis activity. Chem Sci. 2017;8:7521-7.

57. Liu C, Zhao J, Liu J, Guo X, Rao D, Liu H, Zheng P. Simultaneously improving the activity and thermostability of a new proline 4-hydroxylase by loop grafting and site-directed mutagenesis. Appl Microbiol Biotechnol. 2019:103:265-77.

58. Shibasaki T, Mori H, Ozaki A. Enzymatic production of trans -4-hydroxy$\mathrm{L}$-proline by regio- and stereospecific hydroxylation of L-proline. Biosci Biotechnol Biochem. 2000;64:746-50.

59. Espah Borujeni A, Channarasappa AS, Salis HM. Translation rate is controlled by coupled trade-offs between site accessibility, selective RNA unfolding and sliding at upstream standby sites. Nucleic Acids Res. 2014;42:2646-59.

60. Espah Borujeni A, Salis HM. Translation initiation is controlled by RNA folding kinetics via a ribosome drafting mechanism. J Am Chem Soc. 2016;138:7016.

61. Salis HM. The ribosome binding site calculator. In: Voigt C, editor. Synthetic biology, Pt B: computer aided design and DNA assembly. Methods in enzymology, vol. 498. San Diego: Elsevier Academic Press Inc; 2011. p. $19-42$.

62. Zhang $Y$, Zhang $Y$, Shang $X$, Wang $B$, Hu Q, Liu S, Wen T. Reconstruction of tricarboxylic acid cycle in Corynebacterium glutamicum with a genomescale metabolic network model for trans-4-hydroxyproline production. Biotechnol Bioeng. 2019;116:99-109.

63. Chen X, Yi J, Song W, Liu J, Luo Q, Liu L. Chassis engineering of Escherichia coli for trans-4-hydroxy-l-proline production. Microb Biotechnol. 2021;14:392-402.

64. Theodosiou E, Frick O, Buhler B, Schmid A. Metabolic network capacity of Escherichia coli for Krebs cycle-dependent proline hydroxylation. Microb Cell Fact. 2015;14:108.

65. Li M, Ho PY, Yao S, Shimizu K. Effect of sucA or sucC gene knockout on the metabolism in Escherichia coli based on gene expressions, enzyme activities, intracellular metabolite concentrations and metabolic fluxes by 13C-labeling experiments. Biochem Eng J. 2006;30:286-96.

66. Theodosiou E, Breisch M, Julsing MK, Falcioni F, Buhler B. An artificial TCA cycle selects for efficient alpha-ketoglutarate dependent hydroxylase catalysis in engineered Escherichia coli. Biotechnol Bioeng. 2017;114:1511-20.

67. Zhang HL, Zhang C, Pei CH, Han MN, Xu ZD, Li CH, Li W. Efficient production of trans-4-Hydroxy-l-proline from glucose by metabolic engineering of recombinant Escherichia coli. Lett Appl Microbiol. 2018;66:400.

68. Zhang C, Li Y, Ma J, Liu Y, He J, Li Y, Zhu F, Meng J, Zhan J, Li Z, et al. High production of 4-hydroxyisoleucine in Corynebacterium glutamicum by multistep metabolic engineering. Metab Eng. 2018;49:287-98.

69. Long M, Xu M, Ma Z, Pan X, You J, Hu M, Shao Y, Yang T, Zhang X, Rao Z. Significantly enhancing production of trans-4-hydroxy-L-proline by integrated system engineering in Escherichia coli. Sci Adv. 2020;6:2383.

70. Falcioni F, Buhler B, Schmid A. Efficient hydroxyproline production from glucose in minimal media by Corynebacterium glutamicum. Biotechnol Bioeng. 2015:112:322-30.
71. Smith JJ, Lilly MD, Fox RI. The effect of agitation on the morphology and penicillin production of Penicillium chrysogenum. Biotechnol Bioeng. 2010:35:1011-23.

72. Khosla C, Bailey JE. Heterologous expression of a bacterial haemoglobin improves the growth properties of recombinant Escherichia coli. Nature. 1988;331:633-5.

73. Kallio PT, Jin Kim D, Tsai PS, Bailey JE. Intracellular expression of Vitreoscilla hemoglobin alters Escherichia coli energy metabolism under oxygenlimited conditions. Eur J Biochem. 1994;219:201-8.

74. Dikshit RP, Dikshit KL, Liu Y, Webster DA. The bacterial hemoglobin from Vitreoscilla can support the aerobic growth of Escherichia coli lacking terminal oxidases. Arch Biochem Biophys. 1992;293:241-5.

75. Zhao TX, Li M, Zheng X, Wang CH, Zhao HX, Zhang C, Xing XH. Improved production of trans-4-hydroxy-l-proline by chromosomal integration of the Vitreoscilla hemoglobin gene into recombinant Escherichia coli with expression of proline-4-hydroxylase. J Biosci Bioeng. 2017;123:109-15.

76. Eggeling L, Bott M. Handbook of Corynebacterium glutamicum. Boca Raton: Taylor \& Francis; 2005.

77. Kinoshita S, Udaka S, Shimono M. Studies on the amino acid fermentation. Part 1. Production of L-glutamic acid by various microorganisms. J General Appl Microbiol. 2004;50:331-43.

78. Jiang LY, Chen SG, Zhang YY, Liu JZ. Metabolic evolution of Corynebacterium glutamicum for increased production of L-ornithine. BMC Biotechnol. 2013;13:47-47.

79. Becker J, Wittmann C. Bio-based production of chemicals, materials and fuels-Corynebacterium glutamicum as versatile cell factory. Curr Opin Biotechnol. 2012;23:631-40.

80. Zhang Y, Cai J, Shang X, Wang B, Liu S, Chai X, Tan T, Zhang Y, Wen T. A new genome-scale metabolic model of Corynebacterium glutamicum and its application. Biotechnol Biofuels. 2017;10:169-169.

81. Wang J, Zhang Z, Liu H, Sun FF, Yue C, Hu J, Wang C. Construction and optimization of trans-4-hydroxy-L-proline production recombinant E. coli strain taking the glycerol as carbon source. J Chem Technol Biotechnol. 2016;91:2389-98.

82. Falcioni F, Blank LM, Frick O, Karau A, Buhler B, Schmid A. Proline availability regulates proline-4-hydroxylase synthesis and substrate uptake in proline-hydroxylating recombinant Escherichia coli. Appl Environ Microbiol. 2013;79:3091-100.

83. Qi LS, Larson MH, Gilbert LA, Doudna JA, Weissman JS, Arkin AP, Lim WA. Repurposing CRISPR as an RNA-guided platform for sequence-specific control of gene expression. Cell. 2013;152:1173-83.

84. Chen K, Pang Y, Zhang B, Feng J, Xu S, Wang X, Ouyang P. Process optimization for enhancing production of cis -4-hydroxy- I-proline by engineered Escherichia coli. Microb Cell Fact. 2017;16:210.

\section{Publisher's Note}

Springer Nature remains neutral with regard to jurisdictional claims in published maps and institutional affiliations.

Ready to submit your research? Choose BMC and benefit from:

- fast, convenient online submission

- thorough peer review by experienced researchers in your field

- rapid publication on acceptance

- support for research data, including large and complex data types

- gold Open Access which fosters wider collaboration and increased citations

- maximum visibility for your research: over $100 \mathrm{M}$ website views per year

At BMC, research is always in progress.

Learn more biomedcentral.com/submissions 